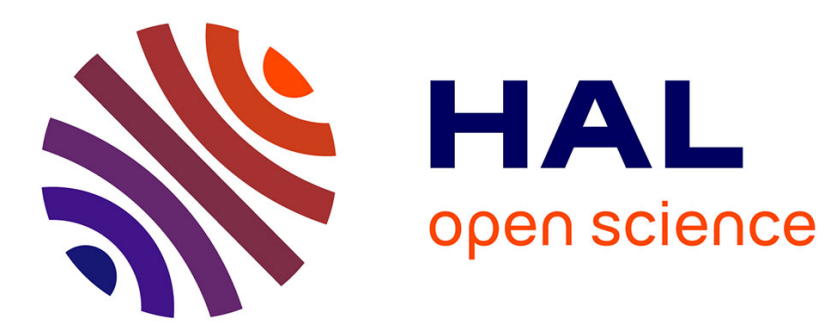

\title{
Nonpeptide antagonists of neuropeptide receptors: tools for research and therapy.
}

Catalina Betancur, Mounia Azzi, William Rostène

\section{To cite this version:}

Catalina Betancur, Mounia Azzi, William Rostène. Nonpeptide antagonists of neuropeptide receptors: tools for research and therapy.. Trends in Pharmacological Sciences, 1997, 18 (10), pp.372-86. inserm00276481

\section{HAL Id: inserm-00276481 https://www.hal.inserm.fr/inserm-00276481}

Submitted on 29 Apr 2008

HAL is a multi-disciplinary open access archive for the deposit and dissemination of scientific research documents, whether they are published or not. The documents may come from teaching and research institutions in France or abroad, or from public or private research centers.
L'archive ouverte pluridisciplinaire HAL, est destinée au dépôt et à la diffusion de documents scientifiques de niveau recherche, publiés ou non, émanant des établissements d'enseignement et de recherche français ou étrangers, des laboratoires publics ou privés. 


\title{
Nonpeptide antagonists of neuropeptide receptors: Tools for research and therapy
}

\author{
Catalina Betancur, Mounia Azzi and William Rostène \\ INSERM U339, Hôpital Saint-Antoine, 184 rue du Faubourg Saint-Antoine, 75571 Paris \\ Cedex 12, France
}

Address correspondence to C. Betancur, e-mail: betancur@adr.st-antoine.inserm.fr

Running title: Nonpeptide antagonists of peptide receptors

Key words: nonpeptide antagonist, peptide receptor, cholecystokinin, tachykinin, neurotensin, neuropeptide $\mathrm{Y}$, angiotensin, corticotropin releasing factor

\section{Summary}

The recent development of selective and highly potent nonpeptide antagonists for peptide receptors has constituted a major breakthrough in the field of neuropeptide research. Following the discovery of the first nonpeptide antagonists for peptide receptors ten years ago, numerous other antagonists have been developed for most neuropeptide families. These new, metabolically stable compounds, orally active and capable of crossing the blood brain barrier, offer clear advantages over the previously available peptide antagonists. Nonpeptide antagonists have provided valuable tools to investigate peptide receptors at the molecular, pharmacological and anatomical levels, and have considerably advanced our understanding of the pathophysiological roles of peptides in the CNS and periphery. Evidence from animal and clinical studies suggests that nonpeptide antagonists binding to peptide receptors could be useful for the treatment of disease states associated with high levels of neuropeptides.

OVER THE PAST TWO DECADES, a large number of novel peptides have been identified in the CNS, many of which fulfill the criteria to be considered potential neurotransmitters. In addition, numerous receptors and receptor subtypes that recognize peptide ligands have been described, based on pharmacological studies. The recent molecular cloning and sequencing of many neuropeptide receptor genes in various species has confirmed and extended the existing classifications. All neuropeptide receptors described so far belong to the G-protein-coupled receptor superfamily, characterized by seven transmembrane spanning regions. Despite the great amount of works dedicated to neuropeptides in the past 
years, our understanding of their role in physiology and disease has been limited by the lack of suitable potent and selective receptor antagonists. Indeed, knowledge about the functional role of classical neurotransmitters has been mostly based on pharmacological studies using specific high-affinity receptor antagonists; until recently, such drugs were not available for neuropeptides, with the exception of opioid receptor antagonists such as naloxone.

Drugs with antagonistic actions for neuropeptide receptors can be classified as either peptides or nonpeptides. Antagonists of a peptide nature are available for several neuropeptides and have been widely used experimentally. However, these antagonists have several drawbacks, including high biodegradability, which precludes oral administration and implies a relatively short duration of action; high molecular weight and thus expensive synthesis; and in general, failure to cross the blood-brain barrier. Other limitations frequently encountered when using peptide antagonists include lack of selectivity for specific receptor subtypes and intrinsic agonistic properties, which contribute to their limited therapeutic and research potential. One of the most exciting advancements in the field of peptide research has been the development of nonpeptide compounds that act as selective antagonists of neuropeptide receptors. Following the discovery of the first nonpeptide antagonist of cholecystokinin (CCK) receptors in 19861,2 (Box 1), many other such compounds have been developed, including nonpeptide antagonists specific for tachykinins (substance $P$ and related neurokinins $A$ and $B$ ), angiotensin II, neurotensin, vasopressin, oxytocin, endothelin, neuropeptide $\mathrm{Y}$ (NPY), bradykinin and corticotropin releasing factor (CRF). In this article we will address the recent developments in nonpeptide antagonists for neuropeptide receptors, with a particular focus on their CNS actions.

\section{Discovery of nonpeptide antagonists}

Two different strategies have been used in the discovery of nonpeptide antagonists of peptide receptors: 1) random screening of large compound libraries, using different biological assays, most frequently radioligand binding; and 2) rational drug-design strategies, i.e., development of a lead compound on the basis of a known peptide ligand. Although several nonpeptide antagonists have been obtained using the rational design approach, including ligands for $\mathrm{CCK}^{3}$ and $\mathrm{NPY}^{4}$, the file screening approach, based initially on natural compounds or, most recently, on synthetic chemicals, has proved most effective. For instance, SR48692, the first potent and selective nonpeptide antagonist of neurotensin receptors, was obtained by optimization of a lead compound discovered by random screening of several thousand chemicals ${ }^{5}$. Moreover, the majority of the nonpeptide tachykinin $\mathrm{NK}_{1}$ and $\mathrm{NK}_{2}$ receptor antagonists available today arose from targeted screening of large compound libraries using a radioligand binding assay as the primary screen ${ }^{6}$, whereas rational drug-design strategies have proved useful for the synthesis of nonpeptide tachykinin antagonists only in limited cases (Box 2). Increasing knowledge concerning 
ligand-receptor interactions will likely facilitate the rational design of novel nonpeptide antagonists with high affinity for peptide receptors.

\section{Molecular interaction of nonpeptide antagonists with their target receptors}

Nonpeptide receptor antagonists are chemically unrelated to the corresponding endogenous agonists, and their mechanism of action is not clear. Within the past few years, however, the molecular interaction of nonpeptide antagonists with their receptors has started to be characterized using applied molecular biology approaches, including receptor expression and site-directed mutagenesis. As most nonpeptide antagonists act as classical competitive ligands, it was initially expected that nonpeptide antagonists would share at least a major part of their binding site with the corresponding peptide agonist. However, it has become increasingly clear that this is seldom the case. The use of antagonist-derived radioligands as well as mutational analysis of receptors has suggested the existence of distinct agonist and antagonist binding domains on receptors for tachykinins ${ }^{7-10}, \mathrm{CCK}^{11,12}$, angiotensin ${ }^{13,14}$, opioids ${ }^{15}$, neurotensin ${ }^{16}$ and vasopressin ${ }^{17}$.

The use of receptor mutagenesis to map binding sites has revealed that most peptide agonists interact primarily with residues located in the exterior part of the receptor, and contact points are frequently found in the N-terminal region (Fig. 1). In contrast, nonpeptide antagonists interact with residues located more deeply in the main ligand binding pocket, between the seven transmembrane segments ${ }^{18}$. Consequently, it has proven extremely difficult to identify point mutations which alter both peptide agonist and nonpeptide antagonist binding. In order to explain these observations, Schwartz and co-workers ${ }^{18}$ have proposed an allosteric receptor model in which the ligands exert their effect by selecting and stabilizing preformed receptor conformations and thus shifting the equilibrium towards either an active or an inactive state. Hence, nonpeptide antagonists bind to the inactive form of the receptor and shift the equilibrium away from the conformation required for agonist binding and receptor activation. The binding sites for agonists and antagonists can be different or overlap, depending on the peptide receptor system. In this receptor model, there is no requirement for an overlap in binding sites between competitive ligands, as the peptide agonist and nonpeptide antagonist act as allosteric competitive ligands by binding in a mutually exclusive fashion to sites occurring in different conformations of the receptor.

\section{Use of nonpeptide antagonists to define receptor subtypes}

Nonpeptide antagonists are currently being developed not only as potential drugs but also as pharmacological and physiological tools. Indeed, the existence of receptor subtypes for several neuropeptides has been established on pharmacological grounds using selective nonpeptide antagonists. For example, the discovery of nonpeptide antagonists which were highly selective for either peripheral or brain CCK receptors provided support for the existence of two subtypes of $\mathrm{CCK}$ receptors (Box 1). $\mathrm{CCK}_{\mathrm{A}}$ receptors are characterized by 
high affinity for the antagonist $L 364718$ (Ref. 2), whereas $\mathrm{CCK}_{\mathrm{B}}$ receptors show high affinity for the antagonist L365260 (Ref. 19). Similarly, the development of nonpeptide angiotensin II receptor antagonists led to the discovery of two pharmacologically and functionally distinct angiotensin receptors (for review, see Ref. 20). The $A T_{1}$ receptor binds the nonpeptide antagonist losartan (DuP753) with high affinity, whereas the $A T_{2}$ receptor is insensitive to losartan but shows high affinity for the antagonist PD123319.

Autoradiography with nonpeptide antagonist as radioligands or to displace agonist labeling has proved particularly useful in studying the distribution of peptide receptors in the CNS and the periphery and to discriminate between different receptor subtypes. For instance, binding of radiolabeled angiotensin II in the presence of selective nonpeptide antagonists revealed the presence of both $A T_{1}$ and $A T_{2}$ receptors in the brain ${ }^{21}$. The central distribution of $\mathrm{AT}_{1}$ receptors is in agreement with their role in mediating all the major physiological actions of angiotensin II, including regulation of blood pressure and water balance ${ }^{20} . \mathrm{AT}_{2}$ receptors are abundant during fetal life and in discrete brain regions but their function remains unclear 22 .

Selective nonpeptide antagonist were also used to study the brain distribution of $\mathrm{CCK}_{\mathrm{A}}$ receptors $^{23}$, which had been previously identified only in the gastrointestinal tract. In autoradiographic experiments, $\mathrm{CCK}_{\mathrm{A}}$ receptors were identified by displacing ${ }^{125}$ /-CCK-8 binding with the $\mathrm{CCK}_{\mathrm{A}}$ antagonist L365031, and by direct labeling with the antagonist ligand ${ }^{3} \mathrm{H}$-L364718. $\mathrm{CCK}_{\mathrm{A}}$ receptors were observed in discrete areas of the rat CNS, including the area postrema and nucleus tractus solitarius, two regions receiving rich vagal input. This localization is in agreement with the role of $\mathrm{CCK}_{\mathrm{A}}$ receptors in the regulation of satiety, through the processing of afferent vagal information from the periphery ${ }^{24}$.

\section{Nonpeptide antagonists reveal different affinity states of neuropeptide receptors}

Radiolabeled ligands derived from nonpeptide antagonists represent useful tools to characterize the different affinity states of neuropeptide receptors. By comparing results obtained from binding of agonist and antagonist radioligands, pancreatic $\mathrm{CCK}_{\mathrm{A}}$ receptors were shown to exist in three different affinity states for the agonist CCK-8; the agonist ligand $\left({ }^{125} \mathrm{I}-\mathrm{CCK}-8\right)$ identified the high- and the low-affinity states, while the antagonist ligand $\left({ }^{3} \mathrm{H}-\right.$ L364718) bound to the low-affinity state and to a previously unidentified very-low-affinity state which represents $80 \%$ of the receptors ${ }^{25}$. The $\mathrm{CCK}_{\mathrm{B}}$ /gastrin receptor also exists in a very low affinity state, detected by the nonpeptide antagonist ${ }^{3} \mathrm{H}-\mathrm{L} 365260$, which recognized a significantly higher number of receptors in the brain and gastric cells than the agonist 125 |CCK-8 (Ref. 26). The ability of radiolabeled nonpeptide antagonists to recognize a larger number of receptors, characterized by low affinity for the agonist, than agonist-derived radioligands, appears to be a common phenomenon. In the guinea-pig brain, the number of binding sites labeled by the nonpeptide neurotensin antagonist radioligand, ${ }^{3} \mathrm{H}-\mathrm{SR} 48692$, exceeded by 20 -fold the number of receptors labeled with the agonist ${ }^{125}$ I-neurotensin (Ref. 
27). The binding sites detected by ${ }^{3} \mathrm{H}-\mathrm{SR} 48692$ were characterized by a low affinity for neurotensin and were insensitive to guanyl nucleotides. These data indicate that the majority (96\%) of neurotensin receptors in the guinea-pig brain exists in a low affinity state for the peptide, representing the G-protein uncoupled form of the receptor, whereas only a small proportion $(4 \%)$ binds neurotensin with a high affinity. These data, together with current hypotheses on the molecular interactions of ligands with their receptors, suggest that radiolabeled agonists and antagonists bind to two complementary populations of receptor conformations ${ }^{18}$. Antagonists bind with high affinity to the G-protein-uncoupled receptors, whereas agonists bind with high affinity to the G-protein-coupled form, but they also bind with low affinity to the G-protein uncoupled form labeled by antagonists.

\section{Species-dependent variations in the binding of nonpeptide antagonists}

In contrast to the endogenous peptide ligands, nonpeptide antagonists often show substantial differences in affinity among species, suggesting that during evolution, peptide receptors have undergone mutations that do not affect the binding of the natural peptide, but frequently modify the nonpeptide antagonist binding sites. The species-related differences in antagonist binding affinity often reflect differences in the primary structure of the receptors. Do these differences represent distinct receptor subtypes or species variants of the same receptor? This question is important not only to clarify the definition of receptor subtypes, but becomes particularly relevant when selecting animal models to test drugs with therapeutic potential.

This concept can be illustrated with the example of tachykinin $\mathrm{NK}_{1}$ receptors, which exhibit profound pharmacological differences among species in their recognition of nonpeptide antagonists. CP96345 has a much lower affinity for rat and mouse $\mathrm{NK}_{1}$ receptors than for $\mathrm{NK}_{1}$ receptors of most species studied, including human, guinea pig and rabbit. The reverse selectivity has been reported for RP67580, which has higher affinity for rat and mouse $\mathrm{NK}_{1}$ receptors. Amino acid sequence comparison of the human and rat $\mathrm{NK}_{1}$ receptor reveals only 22 divergent residues among 407. Analysis of mutant receptors in which divergent residues in the human $\mathrm{NK}_{1}$ receptor were substituted by the rat homologues revealed that substitution of two rat residues at positions 116 and 290 within the transmembrane domain into the human $\mathrm{NK}_{1}$ receptor are sufficient to reproduce the antagonist affinities of the rat receptor ${ }^{9,28}$. Further studies have shown that the species selectivity of several other chemically distinct tachykinin nonpeptide antagonists also depends on the same amino acid residues ${ }^{29}$. Interestingly, guinea pig and mouse $\mathrm{NK}_{1}$ receptors have the same residues at positions 116 and 290 as the human and rat $\mathrm{NK}_{1}$ receptors, respectively, extending to other species the importance of these residues as determinants of the differential affinities of antagonist binding. Thus, the species selectivity of nonpeptide antagonists result from the existence of species variants of the $\mathrm{NK}_{1}$ receptor, 
rather than from different receptor subtypes. Similar inter-species differences in the affinity of nonpeptide antagonists also exist for $\mathrm{NK}_{2}$ and $\mathrm{NK}_{3}$ receptors ${ }^{30,31}$.

The discovery of nonpeptide antagonists for $\mathrm{CCK}_{\mathrm{B}}$ receptors has also led to the observation of differences in antagonist binding affinity between species. Although canine and human $\mathrm{CCK}_{\mathrm{B}}$ receptors share $\sim 90 \%$ amino acid identity and have similar agonist binding affinity, they exhibit opposite rank orders of affinity for two nonpeptide CCK antagonists: L365260 shows selectivity for the human receptor, whereas L364718 displays a higher affinity for the dog CCK receptor. Mutational analysis of the $\mathrm{CCK}_{\mathrm{B}}$ receptor demonstrated that antagonist affinities can be altered dramatically by a single amino acid substitution, which in turn explain species-related differences ${ }^{11}$. The replacement of valine 319 in the sixth transmembrane region of the human receptor with the corresponding amino acid in the canine receptor, leucine, decreases the affinity of L365260 and increases the affinity of L364718 to the values seen in the canine receptor. Conversely, substitution of Leu355 to valine in the canine receptor results in antagonist affinities that resemble those observed in the human receptor. It is interesting to note that these mutations do not alter the affinity of the endogenous peptide ligand, CCK. These results support the concept that differences in amino acid sequence between these species are simply due to a species-specific polymorphism of the same receptor subtype and do not represent novel CCK receptor subtypes.

These studies emphasize the need for species-appropriate models for the screening of antagonists in drug development. Animals used in the screening of nonpeptide antagonists for potential clinical use in humans should have receptors with pharmacological profiles similar to the human homologues. For instance, screening the nonpeptide antagonists CP96345 and RP67580 on rat and mouse $\mathrm{NK}_{1}$ receptors (which have marked affinity differences for these antagonist compared to the human $\mathrm{NK}_{1}$ receptor) would poorly predict pharmacological action in man, whereas guinea pig or rabbit $\mathrm{NK}_{1}$ receptors would be suitable models ${ }^{30}$. This is of particular importance when studying the antinociceptive effects of $\mathrm{NK}_{1}$ antagonists, since most of the animal models of pain classically used employ mice or rats.

\section{Use of nonpeptide antagonists to investigate the role of endogenous peptides}

In order to help in defining receptor function, antagonists must have high specificity in vitro and in vivo and should be devoid of intrinsic or partial agonist activity. As mentioned previously, most peptide antagonists do not meet these requirements, explaining why the advent of nonpeptide receptor antagonists represented a significant progress in the study of the physiological role of neuropeptides.

Recent studies with nonpeptide antagonists of CCK receptors suggest that endogenous CCK plays a role in anxiety, satiety, pain perception, and certain dopamine-mediated behaviors (for review, see Ref. 24). In particular, endogenous CCK modulates dopaminergic transmission in the nucleus accumbens, which is considered the major neural substrate for 
the reinforcing properties of drugs of abuse. Converging evidence suggests that endogenous activation of $\mathrm{CCK}_{\mathrm{B}}$ receptors exerts an inhibitory influence on drug reward and locomotor activation, whereas $\mathrm{CCK}_{\mathrm{A}}$ receptors facilitate these behaviors ${ }^{32}$. Selective $\mathrm{CCK}_{\mathrm{B}}$ antagonists such as L365260 and Cl988 (formerly PD134308) potentiated the rewarding effects of amphetamine and morphine in the conditioned place preference paradigm in rats ${ }^{33,34}$. Conversely, pretreatment with the $\mathrm{CCK}_{\mathrm{A}}$ antagonist devazepide blocked morphine-induced place preference. The effects of endogenous CCK are more readily observed when the dopaminergic systems have been previously stimulated, whereas the role of the peptide under basal activity is more difficult to establish. Several studies have failed to find significant effects on dopamine-related behaviors after administration of $\mathrm{CCK}_{\mathrm{A}}$ or $\mathrm{CCK}_{\mathrm{B}}$ antagonists alone 24,34 . It is probable that special behavioral paradigms may be needed to detect changes due to CCK antagonists, which specifically enhance the activity of dopaminergic neurons to a level likely to induce release of endogenous CCK.

Studies with nonpeptide $\mathrm{CCK}_{\mathrm{B}}$ receptor antagonists have also indicated that endogenous CCK acts as an anxiogenic molecule, since its blockade by the $\mathrm{CCK}_{\mathrm{B}}$ antagonists PD134308 and PD135158 induced potent anxiolytic effects in various animal models ${ }^{3}$. In contrast to benzodiazepines, $\mathrm{CCK}_{\mathrm{B}}$ antagonists did not induce sedation and when administered on a chronic basis, did not induce tolerance nor withdrawal symptoms. Furthermore, $\mathrm{CCK}_{\mathrm{B}}$ antagonists counteracted withdrawal anxiety induced by diazepam. Several other CCK CK $_{B}$ antagonists (L365260, LY262691, LY262684, LY247348, and LY288513), have also demonstrated anxiolytic activity in animal studies. These results strongly support the therapeutic potential of $\mathrm{CCK}_{\mathrm{B}}$ nonpeptide antagonists as anxiolytic agents and suggest that such compounds could be more selective and free of side effects when compared to benzodiazepines.

Exogenous CCK induces satiety and decreases food intake in both animals and humans; before selective antagonists for $\mathrm{CCK}_{\mathrm{A}}$ and $\mathrm{CCK}_{\mathrm{B}}$ receptors became available, it was not known which receptor subtype mediated this response. Numerous studies have now established that the CCK-induced reduction in food intake is blocked by $\mathrm{CCK}_{\mathrm{A}}$, but not $\mathrm{CCK}_{\mathrm{B}}$, receptor antagonists ${ }^{24}$. Studies with the $\mathrm{CCK}_{\mathrm{A}}$ antagonist devazepide, have also provided strong evidence for the role of endogenous CCK in the regulation of feeding. Systemic administration of devazepide increased food intake in rats and mice ${ }^{24}$, and clinical data suggest that CCK could also act as a satiety signal in humans ${ }^{35}$. The $\mathrm{CCK}_{\mathrm{B}}$ antagonist L365260 has also been reported to increase food intake and to postpone the onset of satiety in rats ${ }^{36}$, suggesting that in some situations, endogenous CCK may act on $\mathrm{CCK}_{\mathrm{B}}$ receptors to induce postprandial satiety. In addition, recent findings with selective $\mathrm{CCK}_{\mathrm{B}}$ receptor antagonists have revealed that endogenous CCK is implicated in the perception of pain (for review, see Ref. 37). Specifically, $\mathrm{CCK}_{\mathrm{B}}$ receptor antagonists such as $\mathrm{L} 365260$ and $\mathrm{Cl} 988$ strongly enhanced morphine analgesia and prevented the development of tolerance to the 
analgesic effect of morphine in rats ${ }^{38-40}$. These data raise the possibility that $\mathrm{CCK}_{\mathrm{B}}$ antagonists, alone or in combination with opiates, may be useful in the management of chronic pain.

Thanks to the development of nonpeptide antagonists highly selective for angiotensin receptor subtypes, it was possible to describe novel physiological actions for central $A T_{1}$ receptors, particularly concerning their involvement in the modulation of neurotransmitter systems. In the human brain, $\mathrm{AT}_{1}$ receptors are associated with dopaminergic neurons in the substantia nigra and their terminals in the striatum. Accordingly, angiotensin II increased dopamine turnover in the striatum, an effect which was completely blocked by the $A T_{1}$ selective antagonist, losartan ${ }^{41}$. Administration of losartan alone led to significant depression of DOPAC levels, suggesting that dopamine release is under the tonic facilitatory influence of endogenous angiotensin II. Using similar physiological approaches, $\mathrm{AT}_{1}$ receptors have also been implicated in the central regulation of blood pressure and vasopressin release, through modulation of adrenaline and noradrenaline transmission, respectively.

Much of the current interest in the new nonpeptide neurotensin antagonist SR48692 has been focused on investigating the role of endogenous neurotensin in the modulation of dopaminergic systems. Data obtained with this antagonist indicate that endogenous neurotensin can exert both inhibitory and excitatory effects on dopaminergic activity, confirming the dual action of exogenous neurotensin observed in previous studies following central administration of the peptide. Thus, administration of SR48692 together with a subeffective dose of methamphetamine resulted in a significant increase in locomotion and rearing as well as in the release of dopamine in the nucleus accumbens ${ }^{42}$. SR48692 also potentiated dopamine efflux in the nucleus accumbens evoked by the concomitant administration of haloperidol and electrical stimulation of the medial forebrain bundle; when administered alone, SR48692 did not affect spontaneous dopamine release ${ }^{43}$. By contrast, SR48692 reduced yawning and turning behavior induced by dopaminergic agonists ${ }^{44}$, indicating that neurotensin facilitates the expression of certain behaviors associated with dopamine receptor stimulation. These findings also suggest that the modulatory role of endogenous neurotensin may require previous stimulation of dopaminergic neurons.

The availability of SR48692 has also allowed examination of the effects of endogenous neurotensin in the modulation of the hypothalamic-pituitary-adrenocortical (HPA) axis. Chronic administration of SR48692 at the level of the paraventricular nucleus of the hypothalamus antagonized stress-induced release of ACTH and corticosterone and reduced CRF mRNA levels in the paraventricular nucleus, suggesting that endogenous neurotensin plays a tonic stimulatory role on HPA axis activity ${ }^{45}$. In view of increasing evidence supporting a link between hyperactivity of the HPA axis and depressive disorders ${ }^{46}$, these findings raise the interesting possibility that neurotensin antagonists might be useful in the treatment of affective disorders. 
In agreement with the role of tachykinins in pain transmission and neurogenic inflammation, $\mathrm{NK}_{1}$ receptor antagonists, such as CP96345 (Ref. 47) and RP67580 (Ref. 48), have been shown to possess antinociceptive activity in classical analgesic tests in mice and rats. These findings suggest the utility of tachykinin antagonists as a novel class of analgesic and anti-inflammatory agents. Moreover, a role for tachykinins in the pathogenesis of asthma has been postulated, indicating that tachykinin antagonists could be useful in the treatment of this disease.

\section{Therapeutic potential}

Several nonpeptide antagonists of peptide receptors offer hope as novel therapeutic agents, particularly in the context of clinical findings suggesting that neuropeptides may be hypersecreted in certain pathological states. Following are some examples illustrating the potential use of nonpeptide antagonists in therapy.

\section{Depression, anxiety and stress-related disorders}

Corticotropin releasing factor (CRF) plays a key role in the coordination of the endocrine and behavioral responses to stress and may be involved in the pathophysiology of affective disorders ${ }^{46,49}$. Depressive patients have elevated concentrations of CRF in cerebrospinal fluid, which are normalized after administration of clinically effective antidepressants ${ }^{46}$. These findings suggest the potential utility of CRF receptor antagonists as novel antidepressants. Hypersecretion of endogenous CRF could also be implicated in anxiety-related disorders, since central administration of CRF exerts potent anxiogenic effects in experimental animals. In addition, CRF, as well as urocortin, a recently identified neuropeptide of the CRF family present in the mammalian brain, induce strong appetite-suppressing effects in rats ${ }^{50}$, suggesting a role for these peptides in eating disorders in humans, notably in anorexia nervosa. In agreement with these proposed actions of CRF, peptide CRF antagonists ( $\alpha$ helical CRF9-41 and D-Phe CRF12-41) have been shown to exert anxiolytic effects in several rodent models and inhibit stress-induced decreases in appetitive behavior ${ }^{49}$. However, peptide CRF antagonists have limited utility due to poor solubility and difficulty in penetrating the blood-brain-barrier, as well as weak potency in antagonizing CRF-induced ACTH release. Very recently, several classes of nonpeptide CRF receptor antagonists have been identified $^{51}$. CP154526, the first nonpeptide CRF antagonist described, is highly selective for the $\mathrm{CRF}_{1}$ receptor subtype ${ }^{52}$. Antalarmin is also a nonpeptide $\mathrm{CRF}_{1}$ receptor antagonist ${ }^{53}$. Parenterally administered CP154526 and antalarmin antagonized the stimulatory effects of exogenous CRF on plasma ACTH levels, indicating that these compounds enter the CNS after peripheral administration ${ }^{52,53}$. CP154526 was also effective in decreasing the anxiogenic effects of CRF in rats ${ }^{52}$. Future studies will establish whether the pharmacological properties of these novel nonpeptide CRF antagonists make them good tools for the treatment of disease states associated with high levels of CRF. 
CCK has also been implicated in mediating anxiety and panic attacks. The therapeutic potential of $\mathrm{CCK}_{\mathrm{B}}$ antagonists as anxiolytic agents appears quite promising, as animal studies have indicated that these compounds exert potent anxiolytic effects ${ }^{3}$. Clinical studies have shown that the $\mathrm{CCK}_{\mathrm{B}}$ receptor agonist CCK-4 elicits panic attacks in patients with panic disorders and in healthy volunteers; these effects are antagonized by the nonpeptide $\mathrm{CCK}_{\mathrm{B}}$ antagonist L36526054. However, L365260 was not able to block the endogenous panic attacks not stimulated by CCK-4 in humans ${ }^{55}$. Furthermore, clinical tests performed with the $\mathrm{CCK}_{\mathrm{B}}$ receptor antagonist $\mathrm{Cl} 988$ revealed that this compound was ineffective in patients with generalized anxiety disorder ${ }^{56}$ and also failed to reduce CCK-4 induced symptoms in panic disorder patients ${ }^{57}$. It is possible that this lack of effect is related to the limited solubility and brain penetrability of these first generation $\mathrm{CCK}_{\mathrm{B}}$ antagonists (Box 1).

\section{Neuropsychiatric disorders linked to dopaminergic dysfunction}

Numerous studies indicate that endogenous CCK could be involved in dopamine-related disorders such as schizophrenia, Parkinson's disease and drug addiction 24 . Electrophysiological studies have demonstrated that selective nonpeptide $\mathrm{CCK}_{\mathrm{B}}$ antagonists such as LY262691 and L365260, but not CCK $_{A}$ antagonists, decreased the number of spontaneously active neurons within the $\mathrm{A} 10$ and $\mathrm{A} 9$ nuclei, similarly to what is seen after classic antipsychotic agents ${ }^{58}$. It is interesting to note that dopamine receptor antagonists require chronic administration for 2-3 weeks to be effective, whereas $\mathrm{CCK}_{B}$ antagonists were effective on acute administration. These findings have led to speculation that pharmacological disruption of CCK transmission could be beneficial in the treatment of schizophrenia. However, preliminary clinical trials with the weakly potent and nonselective CCK antagonist proglumide had no apparent effect when administered to patients with schizophrenia or Parkinson's disease. The $\mathrm{CCK}_{\mathrm{A}}$ antagonist loxiglumide was also without effect in a trial with Parkinson's disease. Further clinical trials using the newer, selective nonpeptide CCK receptor antagonists, superior in aqueous solubility, potency and brain penetrability, will be required in order to determine the clinical utility of these compounds in neuropsychiatric disorders.

\section{Hypertension}

Nonpeptide antagonists for the angiotensin II $\mathrm{AT}_{1}$ receptor have been introduced recently for clinical use in the treatment of hypertension and have proved extremely successful 59 . The most prominent example is losartan, an orally active, selective and potent $A T_{1}$ receptor antagonist, that has been found to be an excellent anti-hypertensive drug, safe and without any of the traditional side effects. Other peptides have also been implicated in the pathogenesis of cardiovascular diseases. Vasopressin and endothelin-1 antagonists have potential therapeutic value in the treatment of hypertension, congestive heart failure and ischemic heart disease. The recent synthesis of nonpeptide, orally active, selective antagonists for $\mathrm{V}_{1 \mathrm{~A}}$ receptors ${ }^{60,61}$ (responsible for the vasopressor actions of the peptide) 
and for endothelin receptors ${ }^{62}$ (Table 1 ) is likely to result in the rapid introduction of these antagonists into clinical medicine.

\section{Side-effects?}

Although nonpeptide antagonists for neuropeptide receptors have been evaluated for treatment of a wide range of conditions, most studies have used animal models, and to date, there is little or no experience with human beings concerning the effects of most of the nonpeptide antagonists developed. Drugs that block peptide receptors may be expected to have few if any side-effects. However, the wide variety of actions exerted by most peptides might give rise to potential side-effects. Highly selective antagonists interfere with the actions of the peptide on a given receptor subtype but may result in unwanted side-effects by activating other receptor subtypes. For instance, the current angiotensin receptor antagonists interfere only with the actions of angiotensin II mediated by $\mathrm{AT}_{1}$ receptors. This might result in disinhibition of renin release and increased formation of angiotensin peptides, which could have unexpected effects by activating $A T_{2}$ receptors. Currently there is a search for mixed $\mathrm{AT}_{1} / \mathrm{AT}_{2}$ receptor antagonists that can completely block the effects of angiotensin II.

\section{Concluding remarks}

In the ten years since the report of the discovery of the first nonpeptide antagonist of a nonopioid peptide receptor, more than 100 potent and selective nonpeptide antagonists for several peptides have been developed. The entire neuropeptide field has seen a remarkable advancement, largely fuelled by the availability of effective antagonists with which to study the physiological functions of peptides. This review has highlighted some of the common concepts on nonpeptide antagonists that have emerged during the past few years.

One of the most important contributions coming from the discovery of nonpeptide antagonists has been the characterization of the molecular interactions of nonpeptide ligands with peptide receptors. Pharmacological studies using nonpeptide receptor antagonistderived ligands coupled with molecular biology techniques have considerably increased our knowledge on ligand-receptor interactions. Understanding the molecular interactions responsible for nonpeptide antagonist binding should provide a rational basis for the future development of more potent and selective antagonists for peptide receptors and for related G-protein-coupled receptors.

The use of nonpeptide antagonists to probe the physiological and pathophysiological actions of peptide receptors and their possible therapeutic relevance has proved particularly rewarding. Increasing evidence points out to the role of endogenous neuropeptides as modulators of brain neurotransmitter systems, suggesting the potential therapeutic application of these antagonists in neuropsychiatric disorders associated with altered neurotransmitter activity. 
In spite of the great number of potent and selective neuropeptide antagonists available, it still remains difficult to attribute specific functions to endogenous peptides under basal activity. This might be due to the fact that peptides are usually not released under basal conditions, but are called into play upon activation of the system, when neuronal activity is increased. As reported for co-existing peptides and catecholamines in the CNS and the periphery, the classical neurotransmitter is released at low frequencies of electrical or chemical stimulation, whereas at higher frequencies or during bursting firing the peptide is released together with the classical neurotransmitter ${ }^{63,64}$. Accordingly, neuropeptides may play a role in pathological states, when the system is up-regulated, such as during severe stress or injury, rather than under basal conditions ${ }^{65}$. Therefore, antagonists acting on neuropeptide receptors may become important therapeutic agents, since they may act preferentially on pathologically activated systems. Although the first results obtained in humans have yet to confirm the therapeutic potential of most nonpeptide antagonists of peptide receptors, present available evidence based on animal studies indicates that these agents should be considered as highly promising for the development of new drugs.

\section{Acknowledgement}

C.B. is a recipient of a post-doctoral fellowship from INSERM (Institut National de la Santé et de la Recherche Medicale), France.

\section{Selected References}

1 Evans, B.E. et al. (1986) Proc. Natl. Acad. Sci. U.S.A. 83, 4918-4922

2 Chang, R.S. and Lotti, V.J. (1986) Proc. Natl. Acad. Sci. U.S.A. 83, 4923-4926

3 Hughes, J. et al. (1990) Proc. Natl. Acad. Sci. U.S.A. 87, 6728-6732

4 Lundberg, J.M., Modin, A. and Malmström, R.E. (1996) Trends Pharmacol. Sci. 17, 301-304

5 Gully, D. et al. (1993) Proc. Natl. Acad. Sci. U.S.A. 90, 65-69

6 Watling, K.J. (1992) Trends Pharmacol. Sci. 13, 266-269

7 Fong, T.M., Huang, R.R.C. and Strader, C.D. (1992) J. Biol. Chem. 267, 25664-25667

8 Gether, U. et al. (1993) Nature 362, 345-348

9 Sachais, B.S. et al. (1993) J. Biol. Chem. 268, 2319-2323

10 Rosenkilde, M.M. et al. (1994) J. Biol. Chem. 269, 28160-28164

11 Beinborn, M. et al. (1993) Nature 362, 348-350

12 Mantamadiotis, T. and Baldwin, G.S. (1994) Biochem. Biophys. Res. Commun. 201, 1382-1389

13 Schambye, H.T. et al. (1994) Proc. Natl. Acad. Sci. U.S.A. 91, 7046-7050

14 Hunyady, L., Balla, T. and Catt, K.J. (1996) Trends Pharmacol. Sci. 17, 135-140

15 Kong, H. et al. (1994) Proc. Natl. Acad. Sci. U.S.A. 91, 8042-8046

16 Labbé-Jullié, C. et al. (1995) Mol. Pharmacol. 47, 1050-1056

17 Mouillac, B. et al. (1995) J. Biol. Chem. 270, 25771-25777

18 Schwartz, T.W. et al. (1995) Curr. Pharm. Design 1, 355-372

19 Lotti, V.J. and Chang, R.S. (1989) Eur. J. Pharmacol. 162, 273-280

20 Timmermans, P.B.M.W.M. et al. (1993) Pharmacol. Rev. 45, 205-251

21 Steckelings, U.M., Bottari, S.P. and Unger, T. (1992) Trends Pharmacol. Sci. 13, 365-368

22 Nahmias, C. and Strosberg, A.D. (1995) Trends Pharmacol. Sci. 16, 223-225 
23 Hill, D.R. et al. (1987) J. Neurosci. 7, 2967-2976

24 Crawley, J.N. and Corwin, R.L. (1994) Peptides 15, 731-755

25 Talkad, V.D. et al. (1994) Proc. Natl. Acad. Sci. U.S.A. 91, 1868-1872

26 Chang, R.S.L. et al. (1989) Mol. Pharmacol. 35, 803-808

27 Betancur, C. et al. (1995) J. Pharmacol. Exp. Ther., 273, 1450-1458

28 Fong, T.M., Yu, H. and Strader, C.D. (1992) J. Biol. Chem. 267, 25668-25671

29 Jensen, C.J. et al. (1994) Mol. Pharmacol. 45, 294-299

30 Hall, J.M. et al. (1993) Trends Pharmacol. Sci. 14, 376-383

31 Chung, F.Z. et al. (1995) Mol. Pharmacol. 48, 711-716

32 Vaccarino, F.J. (1994) Neurosci. Biobehav. Rev. 18, 207-214

33 Higgins, G.A., Nguyen, P. and Sellers, E.M. (1992) Brain Res. 572, 208-215

34 Valverde, O. et al. (1996) Psychopharmacology 123, 119-126

35 Wolkowitz, O.M. et al. (1990) Biol. Psychiatry 28, 169-173

36 Dourish, C.T., Rycroft, W. and Iversen, S.D. (1989) Science 245, 1509-1511

37 Wiesenfeld-Hallin, Z. and Xu, X.J. (1996) Regul. Pept. 65, 23-28

38 Dourish, C.T. et al. (1990) Eur. J. Pharmacol. 176, 35-44

39 Wiesenfeld-Hallin, Z. et al. (1990) Proc. Natl. Acad. Sci. U.S.A. 87, 7105-7109

40 Wiertelak, E.P., Maier, S.F. and Watkins, L.R. (1992) Science 256, 830-833

41 Mendelsohn, F.A.O., Jenkins, T.A. and Berkovic, S.F. (1993) Brain Res. 613, 221-229

42 Wagstaff, J.D. et al. (1994) Brain Res. 665, 237-244

43 Brun, P. et al. (1995) J. Neurochem. 64, 2073-2079

44 Poncelet, M. et al. (1994) Psychopharmacology 116, 237-241

45 Nicot, A. et al. (1997) J. Neuroendocrinol. 9, 263-269

46 Barden, N., Reul, J.M.H. and Holsboer, F. (1995) Trends Neurosci. 18, 6-14

47 Snider, R.M. et al. (1991) Science 251, 435-437

48 Garret, C. et al. (1991) Proc. Natl. Acad. Sci. U.S.A. 88, 10208-10212

49 Owens, M.J. and Nemeroff, C.B. (1991) Pharmacol. Rev. 43, 425-473

50 Spina, M. et al. (1996) Science 273, 1561-1564

51 Chalmers, D.T. et al. (1996) Trends Pharmacol. Sci. 17, 166-172

52 Schulz, D.W. et al. (1996) Proc. Natl. Acad. Sci. U.S.A. 93, 10477-10482

53 Webster, E.L. et al. (1996) Endocrinology 137, 5747-5750

54 Bradwejn, J. et al. (1994) Arch. Gen. Psychiatry 51, 486-493

55 Kramer, M.S. et al. (1995) Biol. Psychiatry 37, 462-466

56 Adams, J.B. et al. (1995) J. Clin. Psychopharmacol. 15, 428-434

57 van Megen, HJ et al. (1997) Psychopharmacology 129, 243-248

58 Rasmussen, K. et al. (1991) Eur. J. Pharmacol. 209, 135-138

59 Goodfriend, T.L., Elliott, M.E. and Catt, K.J. (1996) New Engl. J. Med. 334, 1649-1654

60 Yamamura, Y. et al. (1991) Science 252, 572-574

61 Serradeil-Le Gal, C. et al. (1993) J. Clin. Invest. 92, 224-231

62 Ohlstein, E.H. et al. (1996) Med. Res. Rev. 16, 365-390

63 Whim, M.D. and Lloyd, P.E. (1989) Proc. Natl. Acad. Sci. U.S.A. 86, 9034-9038

64 Bean, A.J. and Roth, R.H. (1991) J. Neurosci. 11, 2694-2704

65 Hökfelt, T. (1991) Neuron 7, 867-879 


\section{Box 1. Nonpeptide antagonists for cholecystokinin receptors}

Cholecystokinin (CCK) is one of the most abundant neuropeptides in the mammalian CNS, where it has been implicated in the regulation of anxiety and panic disorder, dopamine-mediated behaviors, satiety and analgesia. CCK receptors exist in two forms: the $\mathrm{CCK}_{\mathrm{A}}$ receptor is found mainly in the gastrointestinal tract, but occurs also in discrete areas in the brain, while the $\mathrm{CCK}_{\mathrm{B}}$ receptor is widely distributed throughout the brain, but is indistinguishable from the gastrin receptor in the periphery. Both subtypes of CCK receptors have recently been cloned and sequenced (for review, see Ref. 1).

The first nonpeptide CCK antagonists were derived from a naturally occurring benzodiazepine, asperlicin, isolated from the fungus Aspergillus alliaceus. This molecule was found by random screening to have selective CCK antagonistic activity, based on radioligand binding to rat pancreas and guinea-pig brain CCK receptors $^{2}$. This work led to the subsequent development of a competitive nonpeptide antagonist, L364718 (also known as devazepide or MK329), with high potency and selectivity for $\mathrm{CCK}_{\mathrm{A}}$ receptors ${ }^{3}$, as well as a selective $\mathrm{CCK}_{\mathrm{B}}$ antagonist, $\mathrm{L}^{2} 65260^{4}$. More recently, other nonpeptide $\mathrm{CCK}_{\mathrm{B}}$ receptor antagonists have been developed. PD134308 (also called C1988) and PD135158 are two potent and highly selective $\mathrm{CCK}_{\mathrm{B}}$ receptor antagonists, derived by rational design from the CCK tetrapeptide ${ }^{5}$. LY262691, obtained from a screening lead, is a $\mathrm{CCK}_{\mathrm{B}}$ antagonist with a brain affinity in the nanomolar range ${ }^{6}$. Another $\mathrm{CCK}_{\mathrm{B}}$ receptor antagonist, YM022, is closely related to L365260, and exhibits high potency and selectivity both in vivo and in vitro ${ }^{7}$. These first generation compounds have provided valuable information concerning the role of CCK in the CNS and the periphery. However, they present some limitations for their use as therapeutic agents, such as poor aqueous solubility, relatively poor oral bioavailability and brain penetration, as well as partial agonistic activity in some tests in vivo.

The second generation of nonpeptide $\mathrm{CCK}_{\mathrm{B}}$ receptor antagonists is characterized by high affinity and selectivity for CCK receptors and increased aqueous solubility. Because the brain penetration of L365260 and related compounds was relatively low, a new series of benzodiazepine derivatives containing a cationic solubilizing group was designed. These antagonists, which include L368935 and L740093, are much more soluble than L365260, with 50-100 times higher affinities for the $\mathrm{CCK}_{\mathrm{B}}$ receptor and with excellent CNS penetration ${ }^{8}$. Another novel family of $\mathrm{CCK}_{\mathrm{B}}$ receptor antagonists includes RP69758, RP71483 and RP72540, which are potent and selective but show very low penetration into the brain ${ }^{9}$. Numerous other subtype-specific CCK receptor antagonists have been since described and further developments in this field can be anticipated, considering the therapeutic potential of these compounds.

\section{References}

1 Wank, S.A. (1995) Am. J. Physiol. 269, G628-G646

2 Chang, R.S.L. et al. (1985) Science 230, 177-179

3 Evans, B.E. et al. (1986) Proc. Natl. Acad. Sci. U.S.A. 83, 4918-4922

4 Bock, M.G. et al. (1989) J. Med. Chem. 32, 13-16

5 Hughes, J. et al. (1990) Proc. Natl. Acad. Sci. U.S.A. 87, 6728-6732

6 Rasmussen, K. et al. (1991) Eur. J. Pharmacol. 209, 135-138

7 Nishida, A. et al. (1994) J. Pharmacol. Exp. Ther. 269, 725-731

8 Patel, S. et al. (1994) Mol. Pharmacol. 46, 943-948

9 Bertrand, P. et al. (1994) Eur. J. Pharmacol. 262, 233-245

Table. Nonpeptide antagonists for cholecystokinin and gastrin receptors

\begin{tabular}{lll}
\hline Receptor subtypes & CCK $_{\mathbf{A}}$ & CCK $_{\mathbf{B}}$ \\
\hline Endogenous ligands & CCK-8 $>>$ gastrin = CCK-4 & CCK-8 $\geq$ gastrin = CCK-4 \\
Selective antagonists & devazepide (L364718, MK329), & L365260, PD134308 (C1988), \\
& L365031, lorglumide (CR1409), & PD135158, LY262684, YM022, \\
& SR27897, FK480, KSG504, & L368935, L740093, RP69758, \\
& PD140548, L743345, T0632 & RP71483, RP72540, RP73870, \\
& LY262691, LY191009, LY242040, \\
& LY202769, LY247348, LY288513, \\
& GV150013, YF476 \\
\hline Mixed CCK $/$ CCK $_{B}$ antagonists & PD142898, FR193108
\end{tabular}




\title{
Box 2. Nonpeptide antagonists for tachykinin receptors
}

The tachykinins constitute a family of neuropeptides comprising substance $P$, neurokinin $A$ and neurokinin $B$, which share a common C-terminal sequence. Tachykinins interact with at least three receptor subtypes, termed $\mathrm{NK}_{1}, \mathrm{NK}_{2}$ and $\mathrm{NK}_{3}$. Substance $\mathrm{P}$ binds preferentially to the $\mathrm{NK}_{1}$ receptor, whereas neurokinin $\mathrm{A}$ and neurokinin $\mathrm{B}$ are the preferred endogenous ligands of the $\mathrm{NK}_{2}$ and $\mathrm{NK}_{3}$ receptors, respectively. Substance $\mathrm{P}$ and related peptides are involved in a variety of biological actions, including pain transmission, vasodilatation, smooth muscle contraction and neurogenic inflammation. In the past few years, several potent and selective nonpeptide antagonists have been discovered, greatly stimulating tachykinin research (for review, see Ref. 1).

The first selective, high affinity, nonpeptide antagonist of the tachykinin $\mathrm{NK}_{1}$ receptor was CP96345, discovered using a ${ }^{3} \mathrm{H}$-substance $\mathrm{P}$ binding assay and random screening of file compounds ${ }^{2}$. This antagonist induced analgesic effects in various rodent models of pain and inflammation. Subsequent studies indicated that CP96345 also interacts with L-type Ca2+ channels, suggesting that the in vivo effects of this compound should not be interpreted only in terms of its action on $\mathrm{NK}_{1}$ receptors. Pfizer's follow-up compound, CP99994, has a high affinity and selectivity for $\mathrm{NK}_{1}$ sites and is essentially devoid of affinity at L-type Ca2+ channels ${ }^{3}$. The second nonpeptide $\mathrm{NK}_{1}$ antagonist, RP67580, discovered using a chemical-file screening approach, was shown to possess antinociceptive activity and was as potent as morphine in various analgesic tests ${ }^{4}$. However, at high concentrations, RP67580 also exerts nonspecific effects on $\mathrm{Ca}^{2+}$ channels. These antagonists show conspicuous differences in their affinities for $\mathrm{NK}_{1}$ receptors from diverse species, due to a few differing amino acids in the receptor sequences. CP96345 has a higher affinity for the human and guinea pig $\mathrm{NK}_{1}$ receptor than for the rat and mouse $\mathrm{NK}_{1}$ receptor, whereas RP67580 shows the reverse species selectivity. PD154075 and CGP49823 are two nonpeptide $\mathrm{NK}_{1}$ antagonists synthesized using rational design strategies, by contrast to the other tachykinin antagonists mentioned above. $\mathrm{NK}_{1}$ receptor antagonists have confirmed the role of endogenous substance $\mathrm{P}$ in nociception, in addition to having therapeutic potential in the treatment of pain, inflammation and asthma. More recently, several $\mathrm{NK}_{1}$ receptor antagonists (including CP99994, GR203040, GR205171 and CP122721) have been shown to possess potent anti-emetic activity, offering the prospect of a novel approach for the control of emesis associated with, for instance, cancer chemotherapy or radiation therapy.

Discovery of the first nonpeptide $\mathrm{NK}_{2}$ receptor antagonists soon followed. SR48968 is a competitive, high affinity antagonist of $\mathrm{NK}_{2}$ receptors; it is orally active, crosses the blood-brain barrier and has long-lasting effects ${ }^{5}$. Although no $\mathrm{NK}_{2}$ binding sites have been visualized in the rat brain, several studies have demonstrated central effects after administration of $\mathrm{NK}_{2}$ receptor agonists that are blocked by $\mathrm{NK}_{2}$ antagonists. For example, SR48968 was reported to block the turning behavior and the firing of thalamic neurons induced by neurokinin A in the rat. SR48968 also inhibited $\mathrm{NK}_{2}$ receptor mediated dopamine release from rat striatum ${ }^{6}$. Both SR48968 and another $\mathrm{NK}_{2}$ antagonist, GR159897, have been reported to exert potent anxiolytic actions in rodent and primate models, suggesting an involvement of tachykinin $\mathrm{NK}_{2}$ receptors in anxiety-related behaviors ${ }^{7}$. These findings support the existence of $\mathrm{NK}_{2}$ receptors in the CNS. The lack of $\mathrm{NK}_{2}$ receptors in the brain in spite of central $\mathrm{NK}_{2}$ receptor mediated responses could suggest that central NK2 receptors differ in their pharmacological properties from peripheral $\mathrm{NK}_{2}$ receptors. Further studies with selective high-affinity $\mathrm{NK}_{2}$ receptor radioligands will be required to clarify this issue.

The first nonpeptide antagonists selective for tachykinin $\mathrm{NK}_{3}$ receptors have recently become available. They include SR142801 (Ref. 8), PD157672 (Ref. 9), and SB223412 (Ref. 10), which will certainly lead to additional understanding of the role of $\mathrm{NK}_{3}$ receptors in brain processes.

\author{
References \\ 1 Regoli, D., Boudon, A. and Fauchère, J.L. (1994) Pharmacol. Rev. 46, 551-599 \\ 2 Snider, R.M. et al. (1991) Science 251, 435-437 \\ 3 McLean, S. et al. (1993) J. Pharmacol. Exp. Ther. 267, 472-479 \\ 4 Garret, C. et al. (1991) Proc. Natl. Acad. Sci. U.S.A. 88, 10208-10212 \\ 5 Emonds-Alt, X. et al. (1993) Regul. Pept. 43, 31-36 \\ 6 Tremblay, L. et al. (1992) Proc. Natl. Acad. Sci. U.S.A. 89, 11214-11218 \\ 7 Walsh, D.M. et al. (1995) Psychopharmacology 121, 186-191
}


8 Emonds-Alt, X. et al. (1995) Life Sci. 56, PL27-PL32

9 Boden, P. et al. (1996) J. Med. Chem. 39, 1664-1675

10 Sarau, H.M. et al. (1997) J. Pharmacol. Exp. Ther. 281, 1303-1311

Table. Nonpeptide antagonists for tachykinin receptors

\begin{tabular}{llll}
\hline Receptor subtypes & NK $_{\mathbf{1}}$ & NK $_{\mathbf{2}}$ & NK $_{\mathbf{3}}$ \\
\hline Endogenous ligands & SP $>$ NKA > NKB & NKA > NKB > SP & NKB > NKA > SP \\
Selective antagonists & CP96345, RP67580, & SR48968, GR159897, & SR142801, PD161182, \\
& SR140333, CP99994, & & SB223412 \\
& WIN51708, WIN62577, & \\
& CGP49823, PD154075, & \\
& LY303870, LY306740, & \\
& L161664, L733060, & \\
& L742694, RPR100893, & \\
& CP122721, CAM4515, & \\
& CAM4750, GR203040, & \\
& GR205171, MEN10930 & \\
Mixed NK $/$ NK $_{2}$ antagonist & MDL105212A & \\
\hline
\end{tabular}

NKA, neurokinin A; NKB, neurokinin B; SP, substance $P$. 


\section{Box 3. Nonpeptide neurotensin receptor antagonists}

Neurotensin is a tridecapeptide widely distributed in the brain and periphery of several mammalian species. Neurotensin is involved in the modulation of dopamine transmission, nociception, hypothermia, and control of anterior pituitary hormone secretion. Until recently, it was believed that neurotensin acted through a single class of G-protein-coupled receptors, cloned in the rat and human. However, in the adult rat and mouse brain, neurotensin can bind to two different binding sites, which can be distinguished by their affinity for NT as well as by their sensitivity to levocabastine, a histamine $\mathrm{H}_{1}$ receptor antagonist. The high affinity site is insensitive to levocabastine and corresponds to the originally cloned receptor in the rat $\left(\mathrm{NT}_{1}\right)$. It was assumed that the low affinity, levocabastine-sensitive binding sites lacked signalling activity and were thus considered as acceptor sites, devoid of function. Very recently, however, a novel neurotensin receptor (called $\mathrm{NT}_{2}$ ) sensitive to levocabastine has been cloned in the rat hypothalamus ${ }^{1}$ and mouse brain ${ }^{2}$. The biological function of $\mathrm{NT}_{2}$ receptors remains to be determined.

A major advancement in the field of neurotensin research was provided by the discovery of the first highly potent and selective nonpeptide neurotensin receptor antagonist, SR48692 (Ref. 3). SR48692 is orally active, crosses the blood-brain barrier and has a long-lasting action; it shows higher affinity for $\mathrm{NT}_{1}$ than for $\mathrm{NT}_{2}$ receptors. This antagonist can counteract the effects of neurotensin in many in vitro and in vivo assays. Given intraperitoneally or orally, SR48692 suppressed the turning behavior ${ }^{3,4}$ and locomotor activity ${ }^{5}$ induced by injection of neurotensin in the striatum or ventral tegmental area, respectively. Central administration of SR48450, an analog of SR48692, antagonized the stimulatory effect of neurotensin on ACTH and corticosterone secretion 6 . However, SR48692 was not able to inhibit neurotensin-induced hypothermia and analgesia in rats and mice ${ }^{7}$. This compound also failed to reverse dopamine release in the nucleus accumbens evoked by neurotensin injection in the ventral tegmental area ${ }^{5}$, as well as the hypolocomotion induced by intracerebroventricular administration of neurotensin ${ }^{8}$. These findings suggest that these effects could be mediated through a neurotensin receptor subtype which is insensitive to SR48692. It would be interesting to assess the potential implication of the recently identified $\mathrm{NT}_{2}$ receptor in mediating the effects of neurotensin not blocked by SR48692.

Although SR48692 has proved an important pharmacological tool for the study of neurotensin receptors and in exploring the existence of possible neurotensin receptor subtypes ${ }^{9}$, it has certain properties that could limit its usefulness. SR48692 has a very low aqueous solubility, which requires administration in nonaqueous vehicles for in vivo studies. More recently, Sanofi has developed a novel nonpeptide antagonist of neurotensin receptors, SR142948A, with better solubility and increased affinity in the rat and human brain ${ }^{10}$. SR $142948 \mathrm{~A}$ recognizes with equally high affinity both $\mathrm{NT}_{1}$ and $\mathrm{NT}_{2}$ receptors. Interestingly, in contrast to SR48692, SR142948A blocked the hypothermia and analgesia induced by central injection of neurotensin, revealing a wider spectrum of action, probably through inhibition of different neurotensin receptor subtypes.

\section{References}

1 Chalon, P. et al. (1996) FEBS Lett. 386, 91-94

2 Mazella, J. et al. (1996) J. Neurosci. 16, 5613-5620

3 Gully, D. et al. (1993) Proc. Natl. Acad. Sci. U.S.A. 90, 65-69

4 Poncelet, M. et al. (1994) Naunyn-Schmiedeberg's Arch. Pharmacol. 349, 57-60

5 Steinberg, R. et al. (1994) Neuroscience 59, 921-929

6 Nicot, A. et al. (1994) Neuroendocrinology 59, 572-578

7 Dubuc, I. et al. (1994) Br. J. Pharmacol. 112, 352-354

8 Pugsley, T.A. et al. (1995) Peptides 16, 37-44

9 Le, F., Cusak, B. and Richelson, E. (1996) Trends Pharmacol. Sci. 17, 1-3

10 Gully, D. et al. (1997) J. Pharmacol. Exp. Ther. 280, 802-812

Table. Nonpeptide antagonists for neurotensin receptors

\begin{tabular}{lll}
\hline Receptor subtypes & $\mathrm{NT}_{1}$ & $\mathrm{NT}_{2}$ \\
\hline Endogenous ligands & $\mathrm{NT}>\mathrm{NN}$ & $\mathrm{NT}=\mathrm{NN}$ \\
Selective antagonists & $\mathrm{SR} 48692$ & - \\
Mixed $\mathrm{NT}_{1} / \mathrm{NT}_{2}$ antagonist & $\mathrm{SR} 142948 \mathrm{~A}$ & \\
\hline
\end{tabular}

$\mathrm{NN}$, neuromedin N; NT, neurotensin. 


\section{Box 4. Neuropeptide $Y$ receptor antagonists}

Neuropeptide Y (NPY) is a 36 amino acid peptide which shares considerable sequence homology with peptide YY (PYY) and pancreatic polypeptide (PP) and is therefore considered a member of the PP family. NPY is one of the most abundant peptides found in the mammalian brain, where it stimulates food intake and modulates the release of a variety of hormones; there is also evidence for an involvement of NPY in the pathophysiology of anxiety (for review, see Ref. 1). In the periphery, NPY is a co-transmitter of the sympathetic nervous system, and participates in cardiovascular control. The effects of NPY and related peptides are mediated through at least six distinct receptor subtypes $\left(Y_{1}-Y_{6}\right)$, all of which have been cloned, except for $Y_{3}$. The $Y_{1}$ and $Y_{2}$ receptors bind NPY and PYY, whereas the $Y_{3}$ receptor binds only NPY. The $Y_{4}$ receptor, also referred to as $\mathrm{PP}_{1}$, has high affinity for PP but substantially lower affinities for NPY and PPY. The $\mathrm{Y}_{5}$ receptor shows equal affinity for NPY and PYY; it is highly expressed in the rat hypothalamus and its pharmacological profile suggests that it might correspond to the so-called feeding receptor ${ }^{2}$. The most recently cloned receptor, $Y_{6}$, is functional in mice, but the human homologue is mutated, representing a non-functional pseudogene ${ }^{3}$. Despite the widespread interest in NPY, the physiological functions of this peptide have been difficult to establish due to the lack of selective antagonists. The therapeutic potential of NPY receptor antagonists in the treatment of cardiovascular diseases and obesity has stimulated intense research efforts from the pharmaceutical industry. The first attempts to synthesize NPY antagonists have yielded a series of peptidergic $Y_{1}$ receptor antagonists (e.g., 1229U91 $)^{4}$, as well as several high affinity, selective, nonpeptide $Y_{1}$ receptor antagonists ${ }^{5}$.

The first generation of nonpeptide $Y_{1}$ receptor antagonists was designed to resemble the C-terminal region of NPY, considered an important site for the interaction with the $Y_{1}$ receptor; it includes BIBP3226 (Ref. 6), SR120107A and SR120819A (Refs. 7, 8). These ligands have nanomolar affinity for $Y_{1}$ receptors in several species and exhibit potent antagonism on $Y_{1}$ receptors in vivo and in vitro. Both SR120107A and SR120819A are orally active and have a long duration of action; in contrast, BIBP3226 lacks oral bioavailability and its antagonistic effect in vivo is relatively short-lasting. Other limitations of this first generation of nonpeptide antagonists include nonspecific $Y_{1}$ unrelated effects and inability to cross the blood-brain barrier. Most of the studies performed to date with these compounds have investigated the role of NPY in vascular control. Interestingly, BIBP3226 did not affect basal blood pressure but attenuated stress-induced hypertension, supporting the hypothesis that NPY is mainly released during stress involving intense activation of the sympathetic nervous system ${ }^{9}$. Although it was initially reported that BIBP3226 (10 nmol i.c.v.) was unable to inhibit NPY-induced feeding behavior in rats $^{2}$, a recent study showed that pretreatment with a higher dose of the antagonist $(60 \mathrm{nmol})$ significantly reduced NPY-induced feeding ${ }^{10}$. Since BIBP3226 does not bind to the rat $Y_{5}$ receptor $^{2}$, these results are against the implication of this receptor subtype in NPY-induced food intake. Future search for more effective nonpeptide $Y_{1}$ receptor antagonists as well as selective antagonists for the other subtypes of NPY receptors will help in the study of the role of endogenous NPY in the regulation of brain functions and will hopefully provide new drugs for the treatment of NPY-related disorders.

\section{References}

1 Balasubramaniam, A. (1997) Peptides 18, 445-457

2 Gerald, C. et al. (1996) Nature 382, 168-171

3 Gregor, P. et al. (1996) J. Biol. Chem. 271, 27776-27781

4 Daniels, A.J. et al. (1995) Proc. Natt. Acad. Sci. U.S.A. 92, 9067-9071

5 Lundberg, J.M., Modin, A. and Malmström, R.E. (1996) Trends Pharmacol. Sci. 17, 301-304

6 Rudolf, K. et al. (1994) Eur. J. Pharmacol. 271, R11-R13

7 Serradeil-Le Gal, C. et al. (1994) Soc. Neurosci. Abstr. 20, 907

8 Serradeil-Le Gal, C. et al. (1995) FEBS Lett. 362, 192-196

9 Doods, H.N. et al. (1996) Regul. Pept. 65, 71-77

10 O'Shea, D. et al. (1997) Endocrinology 138, 196-202

Table. Nonpeptide antagonists for neuropeptide $Y$ receptors

\begin{tabular}{|c|c|c|c|c|c|c|}
\hline Receptor subtypes & $Y_{1}$ & $\mathbf{Y}_{2}$ & $Y_{3}$ & $\mathbf{Y}_{4}$ & $Y_{5}$ & $Y_{6}$ \\
\hline Endogenous ligands & $P Y Y \geq N P Y>P P$ & $P Y Y \geq N P Y>>P P$ & $N P Y \gg P Y Y$ & $P P \gg N P Y=P Y Y$ & $N P Y=P Y Y \geq P P$ & $N P Y=P Y Y>P P$ \\
\hline Selective antagonists & $\begin{array}{l}\text { BIBP3226* } \\
\text { SR120819A } \\
\text { SR120107A }^{+}\end{array}$ & - & - & - & - & - \\
\hline
\end{tabular}

NPY, neuropeptide $Y$; PP, pancreatic polypeptide; PYY, peptide $Y Y$.

* selective relative to $Y_{2}, Y_{3}, Y_{4}$, and $Y_{5}$ receptors ${ }^{2}$

+ selective relative to $Y_{2}$ receptors ${ }^{7,8}$ 


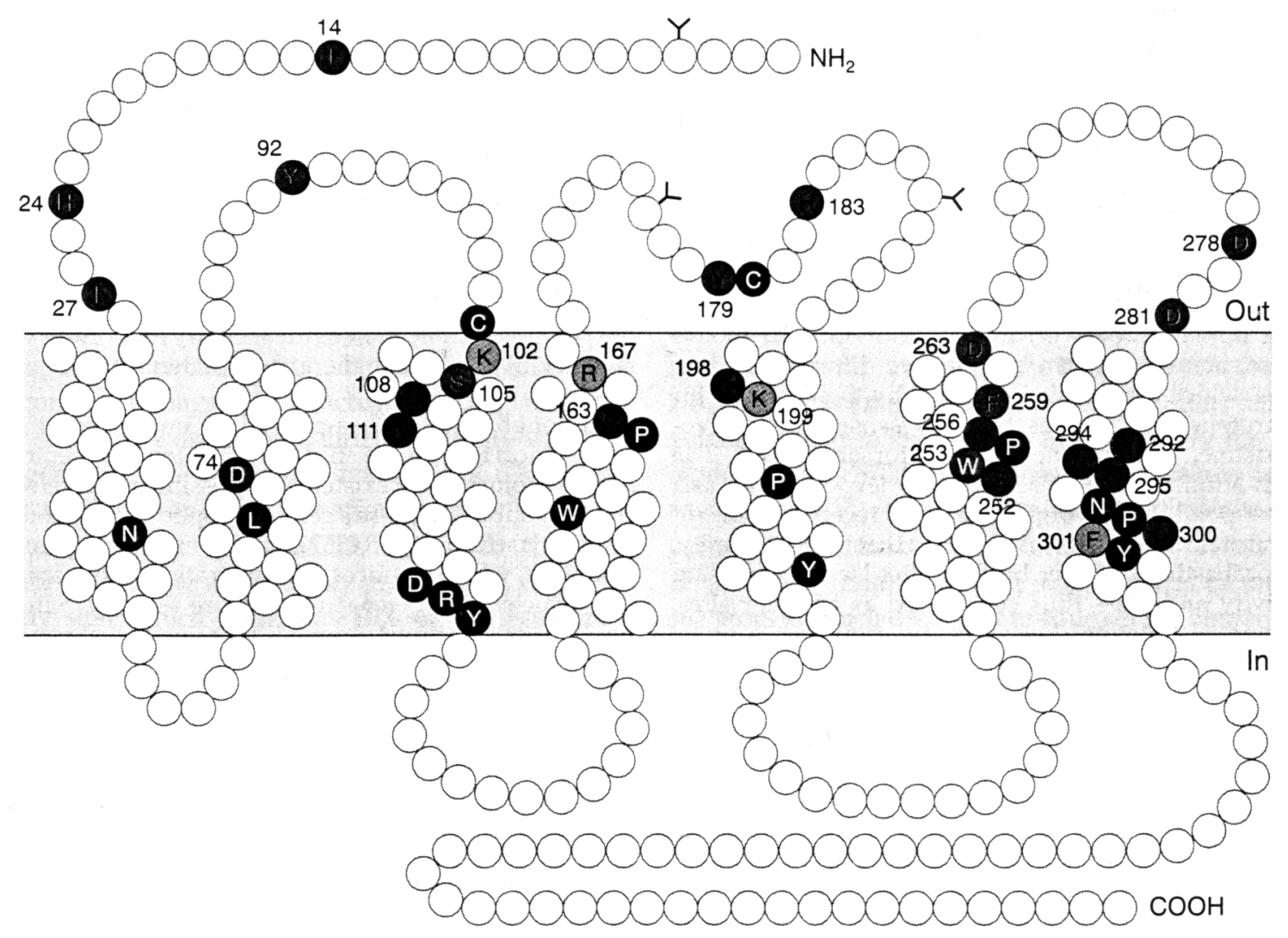

Figure 1. Schematic structure of the angiotensin $A T_{1}$ receptor showing agonist and antagonist binding sites identified by mutational analysis. Amino acids involved in nonpeptide antagonist binding are shown as pink circles, while those implicated in angiotensin II binding are shown as blue circles. Yellow circles indicate residues implicated in both agonist and antagonist binding. The highly conserved fingerprint residues are shown as white letters on black or coloured background. Potential glycosylation sites are also indicated. (Modified from Ref. 14.) 
Table 1. Nonpeptide antagonists for peptide receptors

Angiotensin receptors

Receptor subtypes

Endogenous ligands

Selective antagonists

\section{AT $_{1}$}

Ang II > Ang III

losartan (DuP753, MK954),

DuP532, MK966 (L159282),

irbesartan (SR47436, BMS186295),

telmisartan (BIBR277), SKF108566,

candesartan (TCV116, CV11974),

valsartan (CGP48933), L158809,

SC51316, SC51895, SC52458,

ICID6888, ICID8731, A81282,

A81988, GR117289, BMS180560,

EXP3174, EXP3892,EXP3312,

UP269-6, LR-B/081, UR7198, UR7280,

E4177, CS866, DMP811 (L708404)

Mixed $\mathrm{AT}_{1} / \mathrm{AT}_{2}$ antagonist

BIBS39, BIBS222, L163017, XR510
$\mathrm{AT}_{2}$

Ang II = Ang III

PD123177, PD123319

L161638

\section{Bombesin receptors}

Receptor subtypes

Endogenous ligands

Selective antagonists

Bradykinin receptors

Receptor subtypes

Endogenous ligands

Selective antagonists

\begin{tabular}{lll} 
BB1 & BB2 & BB3 \\
NMB $\geq$ BB $>$ GRP & GRP $\geq B B>$ NMB & BB $>$ GRP = NMB \\
PD165929 & kuwanon H & - \\
\hline B1 & \\
kallidin > BK & B2 \\
- & & kallidin $\geq$ BK \\
& WIN 64338 \\
& FR173657
\end{tabular}

Corticotropin-releasing factor receptors

Receptor subtypes

Endogenous ligands

Selective antagonist

$\mathrm{CRF}_{1}$

urocortin $>$ CRF

CP154526

NB127914

antalarmin

\section{Endothelin receptors}

\section{Receptor subtypes}

Endogenous ligands

Selective antagonists

Mixed $\mathrm{ET}_{\mathrm{A}} / \mathrm{ET}_{\mathrm{B}}$ antagonists

\section{ET $_{\text {A }}$}

$\mathrm{ET}-1=\mathrm{ET}-2>\mathrm{ET}-3$

BMS182874, PD155080,

PD156707, PD159110, PD159433,

TBC11251, A127722, 97-139

bosentan (Ro470203), Ro462005,

SB209670, SB209598, SB217242,

L749329, L754142, L751281,

PD154804, PD159020

\section{Opioid receptors}

Receptor subtypes

Endogenous ligands

Selective antagonists

$\boldsymbol{\mu} \delta$

$\beta$-end $>\operatorname{dyn} A>$ met $>$ leu $\beta$-end $=$ leu $=$ met $>$ dynA

- naltrindole

BNTX

NTB

\section{$\mathrm{ET}$}

$\mathrm{ET}-1=\mathrm{ET}-2$ = ET-3

Ro468443

Nonselective antagonists

naloxone, naltrexone*

\begin{tabular}{lllll}
\hline \multicolumn{2}{l}{ Vasopressin and oxytocin receptors } & & \\
\hline Receptor subtypes & $\mathbf{V}_{\mathbf{1 A}}$ & $\mathbf{V}_{\mathbf{1 B}}$ & $\mathbf{V}_{\mathbf{2}}$ & OT \\
Endogenous ligands & VP $>$ OT & VP $>$ OT & VP $>$ OT & OT $\geq$ VP \\
Selective antagonists & SR49059, OPC21268 & - & OPC31260 & L367773, L368899 \\
& & & & L371257 \\
Mixed $V_{1 A} / V_{2}$ antagonist & YM087 & &
\end{tabular}

*naloxone and naltrexone are weakly selective for $\mu$-opioid receptors.

Abbreviations: Ang II, angiotensin II; Ang III, angiotensin III; $\beta$-end, $\beta$-endorphin; BB, bombesin; BK, bradykinin; CRF, corticotropin-releasing factor; dynA, dynorphin; ET-1, endothelin 1; ET-2, endothelin 2; ET-3, endothelin 3; GRP, gastrin-releasing peptide; kallidin, lysyl-bradykinin; leu, [Leu]enkephalin; met, [Met]enkephalin; NMB, neuromedin B; OT, oxytocin; VP, vasopressin. 


\section{Chemical names}

97-139: 27-O-3-(2-[3-carboxyacryloylamino]-5-hydroxyphenyl)-acryloyloxymyricerone

A127722: trans-trans-2-(4-methoxyphenyl)-4-(1,3-benzodioxol-5-yl)-1-([N,Ndibutylamino]carbonylmethyl)pyrrolidine-3-carboxylate

A81282: 4-(N-butyl- $N$-[\{2'-(1H-tetrazol-5-yl)biphenyl-4-yl\}methyl]amino)pyrimidine-5-carboxylic acid

A81988: 2-( $N$-n-propyl- $N$ - $\{\{2-(1 H$-tetrazol-5-yl)biphenyl-4-yl\}methyl]amino)pyridine-3-carboxylic acid antalarmin: $\mathrm{N}$-butyl- $\mathrm{N}$-ethyl-(2,5,6-trimethyl)-7-[2,4,6-trimethylphenyl]-7 $\mathrm{H}$-pyrrolo[2,3-d]pyrimidin-4yl)amine

BIBP3226: R- $N^{2}$-(diphenylacetyl)- $N$-(4-hydroxyphenyl)methyl-argininamide

BIBS222: 2-n-butyl-1-(4-[6-carboxy-2,5-di-chlorbenzoylamino]-benzyl)-6- $N$-(methylaminocarbonyl)-npentylamino-benzimidazole

BIBS39: 4'-([2-n-butyl-6-cyclohexylaminocarbonylamino-benzimidazole-1-yl]-methyl)biphenylcarboxylic acid

BMS180560: 2-butyl-1-chloro-1-([1-\{2-(2H-tetrazol-5-yl)phenyl\}-1H-indol-4-yl]methyl)-1 $H$-imidazole-5carboxylic acid

BMS182874: 5-(dimethylamino)- $N$-(3,4-dimethyl-5-isoxazolyl)-1-naphthalenesulphonamide

BNTX: (5 $\alpha$ )-17-(cyclopropylmethyl)-4,5-epoxy-3,14-dihydroxy-7-(phenylmethylene)-morphinan-6-one hydrochloride

CAM4515: (S)-[1-(1H-indol-3-ylmethyl)-2-[methyl(phenylmethyl)amino]-2-oxoethyl]-2benzofuranylmethyl ester, carbamic acid

CAM4750: [S- $\left.\left(\mathrm{R}^{\star}, \mathrm{S}^{\star}\right)\right]$-[1-(1H-indol-3-ylmethyl)-1-methyl-2-[methyl[1-(4-pyridinyl)ethyl]amino]-2oxoethyl]-2-benzofuranylmethyl ester monohydrochloride, carbamic acid

CGP49823: [(2R,4S)-2-benzyl-1-(3,5-dimethylbenzoyl)- $N$-[(4-quinolinyl)methyl]-4-piperineamine] dihydrocloride

CP122721: (+)-(2S,3S)-3-(2-methoxy-5-trifluoromethoxybenzyl)amino-2-phenylpiperidine

CP154526: butyl-ethyl-(2,5-dimethyl-7-[2,4,6-trimethylphenyl]-7 H-pyrrolo[2,3-d]pyrimidin-4-yl)amine

CP96345: [(2S,3S)-cis-2-(diphenylmethyl)- $N$-(2-iodophenyl)-methyl]-1-azabicyclo-[2.2.2]octan-3-amine

CP99994: (+)-(2S,3S)-3-(2-methoxybenzylamino)-2-phenylpiperidine

CS866: (5-methyl-2-oxo-1,3-dioxolen-4-yl)methoxy-4-(1-hydroxy-1-methylethyl)-2-propyl-1-(4-[2(tetrazol-5-yl)-phenyl]phenyl)methylimidazol-5-carboxylate

DMP811 (L708404): 4-ethyl-2-n-propyl-1-([2'-\{1H-tetrazole-5-yl\}biphenyl-4-yl]methyl)imidazole-5carboxylic acid

DuP532: 2-propyl-4-pentafluorethyl-1-(2'-[2H-tetrazol-5-yl]-1,1'-biphenyl-4-yl-methyl) $1 H$-imidazole-5carboxylic acid

E4177: 4'-(2-cyclopropyl-7-methyl-3H-imidazo[5,4-b]pyridine-3-yl)methyl-2-biphenylcarboxylic acid

EXP3174: n-butyl-4-chloro-1-([2'-\{1H-tetrazol-5yl\}biphenyl-4-yl]methyl)imidazole-5-carboxylate

EXP3312: 2-n-propyl-4-chloro-1-[(2'-(1H-tetrazol-5-yl)biphenyl-4-yl)methyl]imidazole-5carboxylaldehyde

EXP3892: 2-n-propyl-4-trifluoromethyl-1-[2'-(1H-tetrazol-5-yl)biphenyl-4-yl)methyl]imidazole-5carboxilic acid

FK480: (S)-N-[1-(2-fluorophenyl)-3,4,6,7-tetrahydro-4-oxopyrrolo[3,2,1-jk][1,4]-benzodiazepine-3-yl]$1 \mathrm{H}$-indole-2-carboxamide

FR173657: (E)-3-(6-acetamido-3-pyridyl)- $N$-( $N$-[2,4-dichloro-3\{(2-methyl-8quinolinyl)oxymethyl\}phenyl]- $N$-methylaminocarbonyl-methyl)acrylamide

FR193108: (+)-3-[[5-(2-fluorophenyl)-9-methyl-2-oxo-3-[[[[3-(1 H-tetrazol-5yl)phenyl]amino]carbonyl]amino]-2,3-dihydro-1 $H$-1,4--benzodiazepin-1-yl]acetyl]-3azabicyclo[3.2.2]nonane

GR117289: 1-([3-bromo-2-[2-(1H-tetrazol-5-yl)phenyl]-5-benzofuranyl]methyl)-2-butyl-4-chloro-1 $H$ imidazole-5-carboxylic acid 
GR159897: 5-fluoryl-3-ylethyl(4-[phenylsulphinylmethyl])piperidine

GR203040: (+)-(2S,3S and 2R,2R)-2-methoxy-5-tetrazol-1-yl-benzyl-(2-phenyl-piperidin-3-yl)amine

GR205171: (2S-cis)- $N$-[[2-methoxy-5-[5-(trifluoromethyl)-1 $H$-tetrazol-1-yl]phenyl]methyl]-2-phenyl-3piperidinamine

GV150013: (+)- $N$-(1-[1-adamantane-1-methyl]-2,4-dioxo-5-phenyl-2,3,4,5-tetrahydro-1 H-1,5benzodiazepin-3-yl)- $N$-phenylurea

ICID6888: 2-ethyl-5,6,7,8-tetrahydro-4-([2'-\{1H-tetrazol-5-yl\}biphenyl-4-yl]methoxy)quinoline

ICID8731: 2-ethyl-4-([2'-\{1H-tetrazol-5-yl\}biphenyl-4-yl]methoxy)quinoline

KSG504: (S)-arginium(R)-4-[- $N$-(3-methoxypropyl)- $N$-pentylcarbamoyl]-5-(2naphtylsulfonyl)pentanoate monohydrate

kuwanon H: [1S-(1a,5a,6b)]-8-[6-[2,4-dihydroxy-3-(3-methylbut-2-enyl)benzoyl]-5-(2,4dihydroxyphenyl)-3-methylcyclohex-2-en-1-yl]-2-(2,4-dihydroxyphenyl)-5,7-dihydroxy-3-(3methylbut-2-enyl)-4H-1-benzopyran-4-one

L158809: 5,7-dimethyl-2-ethyl-3-(2-[1H-tetrazol-5-yl]biphenyl-4-yl)imidazol[4,5-b]pyridine

L161638: $N$-[2-ethyl-3-,4-dihydro-4-oxo-3-[[2'-(1H-tetrazol-5-yl)[1,1'-biphenyl]-4-yl]methyl]-6quinazolinyl]- $N$-(phenylmethyl)-2-thiophenecarboxamide

L161664: 1-(N,N-diphenylaminocarbonyl)-4-('N,N-di-n-pentylaminocarbonyl)piperazine-2diethylaminopropylcarboxamide

L163017: 6-(benzoylamino)-7-methyl-2-propyl-3-([2'-\{N-(3-methyl-1butoxy)carbonylaminosulfonyl\}(1,1')-biphenyl-4-yl]methyl)-3H-imidazo(4,5-b)pyridine

L365031: 1-methyl-3-(4-bromobenzoyl)amino-5-phenyl-3H-1,4-benzodiazepin-2-one

L365260: 3R(+)- $N$-(2,3-dihydro-1-methyl-2-oxo-5-phenyl-1 $H$-1,4-benzodiazepin-3-yl)- $N$-(3methylphenyl)urea

L367773: (1S,2S)-2,3-dihydro-1'-(((7,7-dimethyl-2-((4-imidazolylacetyl)amino)bicyclo[2.2.1]hept-1yl)methyl)sulfonyl)spiro( $1 H$-indene-1,4'-piperidine), hydrochloride

L368899: 1-([2-\{2-amino-4-(methylsulphonyl)butyramido\}-7,7-dimethylbicyclo[2.2.1]-heptan-1yl]methylsulphonyl)-4-(2-methylphenyl)piperazine

L368935: $N$-(1,3-dihydro-1-(2-methyl)-propyl-2-oxo-5-phenyl-1H-1,4-benzodiazepin-3-yl)- $N-([3-\{1 H-$ tetrazol-5-yl\}phenyl]urea)

L371257: 1-(1-[4-\{(N-acetyl-4-piperidinyl)oxy\}-2-methoxybenzoyl]piperidinin-4-yl)-4H-3,1-benzoxazin2-1H-one

L733060: (2S,3S)-3-([3,5-bis(trifluoromethyl)phenyl]methyloxy)-2-phenyl piperidine

L740093: $N$-([3R]-5-[3-azabicyclo\{3.2.2\}nonan-3-yl]-2,3-dihydro-1-methyl-2-oxo-1 H-1,4benzodiazepin-3-yl)- $N$-(3-methylphenyl)urea

L742694: 2-(S)-([3,5-bis(trifluoromethyl)benzyl]oxy)-3-(S)-phenyl-4-(5-\{3-oxo-1,2,4triazolo\}methylmorpholine

L743345: 3S- $N$-(3-azabicyclo[3.2.2.]nonan-3-yl-2,3-dihydro-1-methyl-2-oxo-1 H-1,4-benzodiazepin-3yl)-1H-indole-2-carboxamide

L749329: $N$-(2-[4-carboxy-2-propylphenoxy]-2-[dioxolo(e)phenyl]-acetyl)-(4-[1-methylethyl)phenylsulfonylamide

L751281: dipotassium 4-(2-[1,3-benzodioxol-5-yl]-3-[4-isopropylphenylsulphonamido]-3-oxo-prop-1yl)-3-propylbenzoate

L754142: dipotassium (-)-4-(1-[1,3-benzodioxol-5-yl]-2-[4-isopropylphenylsulphonamido]-2oxoethoxy)-3-propylbenzoate

LR-B/081: methyl-2-([4-butyl-2-methyl-6-oxo-5-\{[2'-(1 H-tetrazol-5-yl)[1,1'-biphenyl]-4-yl]methyl\}-1(6H)pyrimidinyl]methyl)-3-thiophenecarboxylate

LY191009: trans-5-(2-chlorophenyl)-3-oxo-4-phenyl- $N$-(4-[trifluoromethyl]phenylpyrazolidine-1carboxamide

LY202769: 2-[2-(5-chloro-1 $H$-indol-3-yl)ethyl]-3-[3-(1-methylethoxy)phenyl]-4(3H)-quinazolinone

LY242040: trans-3-oxo-4,5-diphenyl- $N$-(4-[trifluoromethyl]phenylpyrazolidine-1-carboxamide 
LY247348: 2-[2-(1H-indol-3-yl)ethyl]-3-[3-(1-methylethoxy)phenyl]-4(3H)-quinazolinone

LY262684: trans- $N$-(4-bromophenyl)-4,5-bis(2-chlorophenyl)-3-oxopyrazolidine-1-carboxamide

LY262691: trans- $N$-(4-bromophenyl)-3-oxo-4,5-diphenyl-1-pyrazolidinecarboxamide

LY288513: (4S,5R)- $N$-(4-bromophenyl)-3-oxo-4,5-diphenyl-1-pyrrazolidinecarboxamide

LY303870: (R)-1-(N-[2-methoxybenzyl]acetylamino)-3-(1 H-indol-3-yl)-2-( $N$-[2-\{4-(piperidin-1-

yl)piperidin-1-yl\}acetyl]amino)propane

LY306740: (R)-1-(N-[2-methoxybenzyl]acetylamino)-3-(1H-indol-3-yl)-2-( $N$-[2-\{4-cyclohexylpiperazin1 -yl\}acetyl]amino)propane

MDL105212A: [(R)-1-(2-[3-\{3,4-dichlorophenyl\}-1-\{3,4,5-trimethoxybenzoyl\}-pyrrolidin-3-yl]-ethyl)-4phenylpiperidine-4-carboxamide, hydrochloride

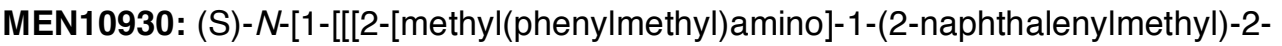
oxoethyl]amino]carbonyl]cyclohexyl]-1H-indole-3-carboxamide

MK966 (L159282): N-(4'-[\{5,7-dimethyl-2-ethyl-3H-imidazo(4,5-b)pyridin-3-yl\}methyl][1,1'-biphenyl]-2yl)sulfonylbenzamide

NB127914: 2-methyl-4-( $N$-propyl- $N$-cyclopropanemethylamino)-5-chloro-6-(2,4,6-tritrichloroanilino)pyrimidine

NTB: naltriben methasulfonate

OPC21268: 1-(1-[4-\{3-acetylaminopropoxy\}benzoyl]-4-piperidil)-3,4-dihydro-2-1 H-quinolinone

OPC31260: 5-dimethylamino-1-(4-[2-methylbenzoylamino]benzoyl)-2,3,4,5-tetrahydro-1 $\mathrm{H}$ benzazepine

PD123177: 1-(4-amino-3-methylphenyl)methyl-3-(diphenylacetyl)-4,5,6,7-tetrahydro-1 H-imidazol[4,5c]pyridine-6-carboxylate

PD123319: (S)-1-(4-[dymethylamino]-3-methylphenyl)methyl-5-(diphenylacetyl)-4,5,6,7-tetrahydro-1 Himidazol[4,5-c]pyridine-6-carboxylate

PD134308 (Cl988): 4-([2-\{(3-[1 H-indol-3-yl]-2-methyl-1-oxo-2-[\{(tricyclo[3.3.1.1 $\left.{ }^{3,7}\right]$ dec-2yloxy)carbonyl\}amino]propyl)amino\}-1-phenylethyl]amino)-4-oxo-( $\left.R-\left[R^{*}, R^{\star}\right]\right)$-butanoate- $N$-methyl-Dglucamine

PD135158: 4-([2-\{(3-[1H-indol-3-yl]-2-methyl-1-oxo-2-[\{(1.7.7-trimethyl-(bicyclo[2.2.1]hept-2yl)oxy)carbonyl\}amino]propyl)amino\}-1-phenylethyl]amino)-4-oxo-[1S-1 $\left.\left.\alpha .2 \beta\left[S^{*}\left(S^{*}\right)\right] 4 \alpha\right]\right)$-butanoate$N$-methyl-D-glucamine (bicyclo system 1S-endo)

PD140548: $N$-( $\alpha$-methyl- $N$-[\{tricyclo(3.3.1.1 $\left.1^{3,7}\right)$ dec-2-yloxy\}carbonyl]-L-tryptophyl)-D-3-(phenylmethyl)$\beta$-alanine

PD142898: benzenebutanic acid, $\beta-([3-\{1 H$-indol-3-yl $\}-2-m e t h y l-2-[\{[(2-$ methylcyclohexyl)oxy]carbonyl\}amino]-1-oxopropyl]amino)-(1S-[1 $\left.\left.\alpha\left\{S^{*}\left(R^{*}\right)\right\}-2 \beta\right]\right)$

PD154075: [R-( $\left.\left.\mathrm{R}^{\star}, \mathrm{S}^{\star}\right)\right]-[1-(1 H$-indol-3-ylmethyl)-1-methyl-2-oxo-2-[(1-phenylethyl)amino]ethyl]-2benzofuranylmethyl ester, carbamic acid

PD154804: 3-(1,3-benzodioxol-5-yl)-4-cyclohexylmethyl-5-hydroxy-5-(4-methoxyphenyl)-2,5dihydrofuran-2-one

PD155080: 2-benzo(1,3)dioxol-5-yl-3-benzyl-4-(4-methoxyphenyl)-4-oxobut-2-enoate

PD156707: 2-benzo(1,3)dioxol-5-yl-4-(4-methoxyphenyl)-4-oxo-3-(3,4,5-trimethoxybenzyl)-but-2enoate

PD159020: 3-(1,3-benzodioxol-5-yl)-1-(1,3-benzodioxol-5-ylmethyl)-5-methoxy-6-(phenylmethoxy)-1Hindole-2-carboxylic acid

PD159110: 3-(1,3-benzodioxol-5-yl)-1-(1,3-benzodioxol-5-ylmethyl)-6-propoxy-1H-indole-2-carboxylic acid

PD159433: 1-(1,3-benzodioxol-5-ylmethyl)-5,6-dimethoxy-3-[(3,4,5-trimethoxyphenyl)thio]-1 $H$-indole2-carboxylic acid

PD161182: [S-( $\left.\left.R^{*}, S^{*}\right)\right]-[2-(2,3-d i f l u r o p h e n y l)-1-m e t h y l-1-\{(7-$ ureidoheptyl)carbamoyl\}ethyl]carbamic acid-2-methyl-1-phenylpropyl ester

PD165929: (S)- $\alpha$-[[[[2,6-bis(1-methylethyl)phenyl]amino]carbonyl]amino]- $\alpha$-methyl- $N-[[1-(2-$ 
pyridinyl)cyclohexyl]methyl]-1H-indole-3-propanamide

Ro462005: 4-tert-butyl- $N$-(6-[2-hydroxyetoxy]-5-[3-methoxyphenoxy]-4-pyrimidinyl)benzenesulphonamide

Ro468443: (R)-4-tert-butyl-N-(6-[2,3-dihydroxypropoxy]-5-[2-methoxyphenoxy]-2-[4-methoxyphenyl]pyrimidin-4-yl)-benzenesulphonamide

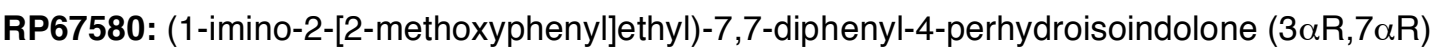

RP69758: 3-(3-[N-\{N-methyl- $N$-phenyl-carbamoylmethyl\}- $N$-phenylcarbamoylmethyl]ureido) phenylacetic acid

RP71483: (E)-2-(3-[3-hydroxyiminomethyl-phenyl]ureido)- $N$-(8-quinolyl)- $N$-([1,2,3,4-tetrahydro-1quinolyl]carbonylmethyl)acetamide

RP72540: (RS)-2-(3-[3-\{N-(3-methoxyphenyl)- $N$-( $N$-methyl- $N$-phenylcarbamoylmethyl)carbamoylmethyl\}ureido]phenyl)propionic acid

RP73870: (RS)-([\{N-(3-methoxyphenyl)- $N$-( $N$-methyl- $N$-phenyl-carbamoylmethyl)carbamoylmethyl\}-3ureido]-3-phenyl)-2-ethylsulfonate, potassium salt

RPR100893: (3nS,4S,7aS)-7,7-diphenyl-4-(2-methoxyphenyl)-2-[(S)-2-(2methoxyphenyl)propionyl]perhydroisoindol-4-ol

SB209598: 3-(2-carboxymethoxy-4-methoxyphenyl)-1-(6-chloro-1,3-benzodioxol-5-ylmethyl)-indole-2carboxilic acid

SB209670: (+)-1S,2R,S-3-(2-carboxymethoxy-4-methoxyphenyl)-1-(3,4-methylenedioxyphenyl)-5prop-1-yloxyindane-2-carboxylic acid

SB217242: 1S,2R,3S-3-(2-hydroxyethoxy-4-methoxyphenyl)-1-(3,4-methylenedioxyphenyl)-5propoxyindane-2-carboxylic acid

SB223412: (S)-(-)- $N$-( $\alpha$-ethylbenzyl)-3-hydroxy-2-phenylquinoline-4-carboxamide

SC51316: 5-([3,5-dibutyl-1H-1,2,4-triazol-1-yl]methyl)-2-(2-[1H-tetrazol-5-ylphenyl])pyridine

SC51895: 1,4-dibutyl-1,3-dihydro-3-([2'-\{1H-tetrazol-5-yl\}[1,1'-biphenyl]-4-yl]methyl)-2H-imidazol-2-one

SC52458: 2,5-dibutyl-2,4-dihydro-4-([2-\{1H-tetrazol-5-yl\}[1,1'-biphenyl]-4'-yl]methyl)-3H-1,2,4-triazol-3one

SKF108566: (E)- $\alpha$-([2-butyl-1-\{(4-carboxyphenyl)methyl $\}-1 H$-imidazol-5-yl]methylene)-2thiophenepropanoate

SR 48692: 2-([1-\{7-chloro-4-quinolinyl\}-5-\{2,6-dimethoxyphenyl\}-1 H-pyrazol-3carbonyl]amino)adamantane-2-carboxylic acid

SR120107A: $(R, R)-1-(2-[2-\{2-n a p h t y l s u l p h a m o y l\}-3-p h e n y l-p r o p i o n a m i d o]-3-[4-\{N-(4-$ [dimethylaminomethyl]-cis-cyclohexylmethyl)amidino\}phenyl]propionyl)-pyrrolidine

SR120819A: (R,R)-1-(2-[2-\{2-naphtylsulphamoyl\}-3-phenyl-propionamido]-3-[4-\{N-(4[dimethylaminomethyl]-trans-cyclohexylmethyl)amidino\}phenyl]propionyl)-pyrrolidine

SR140333: (S)-1-(2-[3-\{3,4-dichlorophenyl\}-1-\{3-isopropoxyphenylacetyl\}piperidin-3-yl]ethyl)-4-phenyl1-azoniabicyclo(2.2.2)octane chloride

SR142801: (S)-( $M)$-(1-[3-\{1-benzoyl-3-(3,4-dichlorophenyl)piperidin-3-yl\}propyl]-4-phenylpiperidin-4yl) $-N$-methylacetamide

SR142948A: 2-([5-\{2,6-dimethoxyphenyl\}-1-\{4-(N-[3-dimethylaminopropyl]- $N$-methylcarbamoyl)-2isopropylphenyl\}-1 $\mathrm{H}$-pyrazol-3-carbonyl]amino)adamantane-2-carboxylic acid, hydrochloride

SR27897: 1-([2-\{4-(2-chlorophenyl)thiazole-2-yl\}aminocarbonyl]indolyl)acetic acid

SR48968: (S)- $N$-methyl- $N$-(4-acetylamino-4-phenylpiperidino)-2-(3,4-dichlorophenyl)butylbenzamide

SR49059: (2S)-1-([2R,3S]-[5-chloro-3-\{chlorophenyl\}-1-\{3,4-dimethoxysulphonyl\}-3-hydroxy-2,3dihydro-1 $H$-indole-2-carbonyl]-pyrrolidine-2-carboxamide)

T0632: sodium (S)-3-(1-[2-fluorophenyl]-2,3-dihydro-3-[\{3-isoquinolinyl\}-carbonyl]amino-6-methoxy-2oxo-1 1 -indole)propanoate

TBC11251: N-(4-chloro-3-methyl-5-isoxazolyl)-2-[2-(6-methyl1,3-benzodioxol-5-yl)-1-oxoethyl]thiopentene-3-sulphonamide

UP269-6: 5-methyl-7-propyl-8(-)[2'-(1H-tetrazol-5-yl)biphenyl-4-yl)methyl]-1,2,4-triazolo]1,5- 
c]pyrimidin-2(3H)-one

UR7198: rel-(1 $\left.\mathrm{R}^{\star}, 2 \mathrm{R}^{\star}\right)$-3-[[4-(2-carboxy-1-phenylpropyl)phenyl]methyl]-5,7-dimethyl-2-ethyl-3Himidazol[4,5-b]pyridine

UR7280: 3-tert-butyl-1-propyl-5-([2'-\{1H-tetrazol-5-yl\}-1,1'-biphenyl-4-yl]methyl)-1H-pyrazole-4carboxylic acid

WIN 64338: ([4-\{(2-[\{bis(cyclohexylamino)methylene\}amino]-3-[2-naphthyl]-1oxopropyl)amino\}phenyl]methyl)tributylphosphonium chloride monohydrochloride

WIN51708: $17 \beta$-hydroxy-17 $\alpha$-ethynyl-5 $\alpha$-androstanol[3,2-b]pyrimido[1,2-a]benzimidazole

WIN62577: [1R-( $1 \alpha, 3 a \beta, 3 b \alpha, 15 a \alpha, 15 b \beta, 17 a \alpha)]-1$ ethynyl-2,3,3a,3b,4,5,15,15a,15b,16,17,17adodecahydro-15a,17a-dimethyl-1 $H$-benzimidazo[2,1-b]cyclopenta[5,6]naphto[1,2-g]quinazolin-1-ol

XR510: 1-([2'-\{[(isopentoxycarbonyl)amino]sulfonyl\}-3-fluoro(1,1'-biphenyl)-4-yl]methyl)-5-(3-[Npyridin-3-ylbutanamido]propanoyl)-4-ethyl-2-propyl-1 $H$-imidazole, potassium salt

YF476: (3R)- $N$-(1-[tert-butylcarbonylmethyl]-2,3-dihydro-2-oxo-5-[2-pyridil]-1 H-1,4-benzodiazepin-3yl)- $N$-(3-[methylamino]phenyl)urea

YM022: (R)-1-(2,3-dihydro-1-[2'-methylphenacyl]-2-oxo-5-phenyl-1 H-1,4-benzodiazepin-3-yl)-3-(3methylphenyl)urea

YM087: 4'-(2-methyl-1,4,5,6-tetrahydroimidazo\{4,5-d\} 1\}benzazepin-6-yl]carbonyl)-2phenylbenzanilide monohydrocloride 